\title{
Resposta de cultivares de feijão à alta temperatura do ar no período reprodutivo
}

\author{
Response of beans cultivars to high air temperature in the reproductive period
}

\author{
Leo Hoffmann Júnior ${ }^{I}$ Nerinéia Dalfollo Ribeiro**I \\ Simone Saydelles da Rosa ${ }^{\text {III }}$ Evandro Jost ${ }^{\mathrm{I}}$ Nerison Luis Poersch ${ }^{\text {III }}$ \\ Sandro Luís Petter Medeiros ${ }^{\mathrm{II}}$
}

RESUMO

$O$ rendimento de grãos do feijão é afetado pela ocorrência de alta temperatura do ar, durante o período reprodutivo. Sendo assim, foi objetivo do trabalho avaliar a variabilidade genética do feijão para tolerância à alta temperatura do ar durante o período de pré-floração (R5) à formação de vagens (R7). O experimento foi conduzido em câmara de crescimento (fitotron), com controle de temperatura, luz, fotoperíodo e demais condições ótimas de cultivo. Durante o subperíodo $R 5-R 7$, as plantas foram submetidas à temperatura de $30^{\circ} \mathrm{C}$, durante uma hora, diariamente. $\mathrm{O}$ delineamento experimental utilizado foi o inteiramente casualizado, com três repetições, e avaliaram-se 20 cultivares de feijão. Comportamento diferenciado foi observado para as características fenológicas, reprodutivas e dos componentes da produção, indicando variabilidade genética para tolerância à alta temperatura do ar durante o subperíodo R5-R7. As cultivares de feijão "Pérola", "TPS Bonito", "BRS Valente" $e$ "Corrente" são tolerantes à temperatura do ar de $30^{\circ} \mathrm{C}$ por uma hora, durante o período reprodutivo.

Palavras-chave: Phaseolus vulgaris L., abortamento de flores, seleção de cultivares.

\section{ABSTRACT}

Common bean grain yield is affected by high air temperature during the reproductive period. This study was aimed at evaluating common bean genetic variability for tolerance to high air temperature during the pre-flowering (R5) and pod formation (R7) period. The experiment was conducted in a phytotron, with controlled air temperature, light and photoperiod and other conditions for optimum growth. During the R5-R7 period, plants were exposed to $30^{\circ} \mathrm{C}$ air temperature during one hour a day. The experimental design used was a completely randomized with three replications and
20 common bean cultivars. Differences in phenological and reproductive traits and yield components, indicated genetic variability for tolerance to high air temperature during the R5$R 7$ period. Cultivars 'Pérola', 'TPS Bonito', 'BRS Valente' and 'Corrente' were tolerant to air temperature of $30^{\circ} \mathrm{C}$ during one hour a day during the reproductive period.

Key words: Phaseolus vulgaris L., flower abortion, cultivar selection.

\section{INTRODUÇÃO}

O feijão é uma cultura de ciclo curto e, por isso, mais sensível às variações das condições ambientais. As altas temperaturas e a seca são problemas para o cultivo em muitas regiões do Brasil, especialmente no Nordeste, onde a produção é comprometida em mais de 1,5 milhão de hectares (TÉRAN \& SINGH, 2002).

A temperatura do ar é fator determinante para a exploração comercial do feijão em várias regiões. Essa espécie é cultivada sob temperaturas variando de 10 a $35^{\circ} \mathrm{C}$ (MARIOT, 1989), sendo a faixa de 18 a $24^{\circ} \mathrm{C}$ considerada ótima, de acordo com VIEIRA (1967). No entanto, a ocorrência de temperaturas superiores a 30/ $32^{\circ} \mathrm{C}$ durante o transcorrer do dia resulta em prejuízos ao estabelecimento, crescimento e desenvolvimento da cultura (GONÇALVES et al., 1997; ANDRADE, 1998; MASSIGNAM et al., 1998).

No município de Santa Maria-RS, os valores médios da temperatura máxima do ar situam-se na faixa

\footnotetext{
IPrograma de Pós-graduação em Agronomia, Universidade Federal de Santa Maria (UFSM), 97105-900, Santa Maria, RS, Brasil.

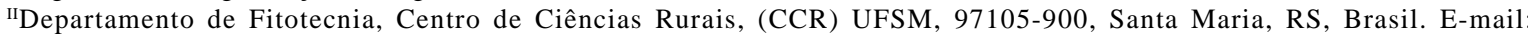
neiadr@smail.ufsm.br.*Autor para correspondência.

${ }^{\text {IIIC } C u r s o ~ d e ~ A g r o n o m i a ~ d a ~ U F S M . ~}$
} 
entre 28 a $29^{\circ} \mathrm{C}$ e de 31 a $32^{\circ} \mathrm{C}$ nos meses de novembro e dezembro, respectivamente (BURIOL et al., 1979), período em que, normalmente, o feijão encontra-se no período reprodutivo. Existe uma probabilidade de $46 \%$ e de $80 \%$ para que ocorra uma seqüência de quatro dias consecutivos com valores máximos de temperatura do ar igual ou superior a $30^{\circ} \mathrm{C}$, nos meses de novembro e dezembro (ESTEFANEL et al., 1994), o que afeta a produtividade da cultura.

Dependendo do tempo em que a temperatura permanecer acima de $30^{\circ} \mathrm{C}$, do valor máximo atingido e do número de dias consecutivos em que ocorrer essa condição, os danos observados podem ser mais severos (BARBANO et al., 2001). Assim, sob condições de alta temperatura do ar, têm sido observadas reduções entre 30,7 e 75,5\% na produtividade de grãos de feijão (MODA-CIRINO\& FONSECAJÚNIOR, 2001; AGUIAR \& MODA-CIRINO, 2002a;AGUIAR \& MODA-CIRINO, 2002b).

A alta temperatura do ar talvez seja o fator ambiental que exerça maior influência sobre a abscisão de flores e de vagens, o não-enchimento adequado de grãos, o vingamento e a retenção final de vagens no feijão, sendo também responsável pela redução do número de sementes por vagem e pela menor massa de sementes (PORTES, 1996; GONÇALVES et al., 1997; DIDONET \& MADRIZ, 2002; DIDONET et al., 2002). Nos estádios de pré-floração (R5) e enchimento de vagens (R8), o feijão é mais afetado pela alta temperatura (SHONNARD \& GEPTS, 1994).

Normalmente, a taxa de abscisão dos órgãos reprodutivos atinge de 50 a $70 \%$ do total de flores abertas (MARIOT, 1989). Mas, em condições de alta temperatura do ar, o incremento na taxa de abortamento de flores supera de 20 a $50 \%$ o valor obtido no cultivo sem estresse térmico, para as cultivares "Pérola" e "Valente” (DIDONET, 2001). Além disso, presença de variabilidade genética para tolerância à alta temperatura do ar no período reprodutivo tem sido constatada em cultivares de feijão (SILVEIRA et al., 1980; SHONNARD \& GEPTS, 1994; MODA-CIRINO \& FONSECA JÚNIOR, 2001; AGUIAR \& MODA-CIRINO, 2002a; AGUIAR \& MODA-CIRINO, 2002b; SILVA et al., 2005).

Efeito gênico aditivo para tolerância à alta temperatura foi verificado nos estádios R5 e R8, o que sugere oportunidades para ganhos na seleção dessa característica, que apresenta herança quantitativa (DICKSON \& PETZOLDT, 1989; SHONNARD \& GEPTS, 1994). Como presença de interação genótipo x ambiente para essa característica foi constatada (SHONNARD \& GEPTS, 1994), isso implica a necessidade de identificação de cultivares de feijão apropriadas para o cultivo em áreas consideradas de risco climático.
A maioria dos trabalhos realizados para avaliar os efeitos prejudiciais da ocorrência de valores elevados de temperatura do ar sobre o feijão foram conduzidos no campo. Nessa condição, não se tem controle da intensidade e da duração da temperatura do ar limitante às plantas de feijão. Por essa razão, os cultivos realizados em câmaras de crescimento (fitotron) são mais apropriados para a avaliação dos danos causados ao feijão em decorrência de altas temperaturas. Assim, o objetivo do trabalho foi avaliar a variabilidade genética do feijão para tolerância à alta temperatura do ar durante o período reprodutivo.

\section{MATERIAL E MÉTODOS}

O experimento foi conduzido em uma câmara controlada (fitotron), instalada no Laboratório de Análise de Qualidade, do Departamento de Fitotecnia, da Universidade Federal de Santa Maria, Santa MariaRS.

O fitotron - com as dimensões de 3,10m comprimento x 1,90m largura x 2,50m altura - foi pintado internamente de branco para melhor aproveitamento da luz. A luz foi fornecida através de lâmpadas fluorescentes (40W) e incandescentes (100W), em uma proporção de 4:1, fornecendo um total de $400,68 \mathrm{~W} \mathrm{~m}^{-2} \mathrm{e}$ um fotoperíodo de 16 horas de luz e 8 horas de escuro. A temperatura do ar foi controlada através de condicionador de ar de 10.000 BTUS e termohigrógrafo, instalados no interior do fitotron.

O delineamento utilizado foi inteiramente casualizado, com três repetições, e os tratamentos foram compostos de 20 cultivares de feijão (Tabela 1). A unidade experimental foi constituída por vaso plástico com uma planta, com capacidade para aproximadamente 5 litros de substrato comercial Plantmax ${ }^{\circledR}$, definido em experimento prévio. Os vasos foram acomodados sobre bancadas de $70 \mathrm{~cm}$ de altura.

Os elementos minerais foram fornecidos em doses semanais através da fertirrigação com a solução nutritiva proposta por HOAGLAND \& ARNON (1950), porém utilizando a metade da dose de nitrato recomendada. A água foi adicionada de maneira a repor o volume consumido pelas plantas, sendo o excedente eliminado através da drenagem natural.

Amostras da solução drenada foram coletadas semanalmente para a leitura da condutividade elétrica. Sempre que a leitura ultrapassou o valor de 3,0 $\mathrm{mS} . \mathrm{cm}^{-1}$, foi realizada uma irrigação abundante para lixiviar o excesso de sais do substrato.

A simulação da ocorrência de alta temperatura do ar foi realizada quando as plantas de feijão encontravam-se entre os estádios reprodutivos

Ciência Rural, v.37, n.6,nov-dez, 2007. 
Tabela 1 - Caracterização da coloração do tegumento dos grãos (COR), hábito de crescimento (HC), número de dias da semeadura à emergência (EMER), número de dias da emergência à floração (FLOR) e número de dias da emergência à maturação fisiológica (CICLO) de cultivares de feijão submetidas à temperatura de $30^{\circ} \mathrm{C}$, por uma hora, durante o período reprodutivo. Santa MariaRS, UFSM, 2006

\begin{tabular}{|c|c|c|c|c|c|}
\hline Cultivates & $\mathrm{COR}$ & HC** & EMER & FLOR & CICLO \\
\hline & & & & $\ldots$ dias ... & \\
\hline "Iraî" & creme com estrias roxas & I & $7,0 a^{*}$ & $22,7 \mathrm{c}$ & $82,0^{\mathrm{ns}}$ \\
\hline “PR 468” & creme com estrias roxas & I & $6,3 \mathrm{~b}$ & $22,7 \mathrm{c}$ & 72,0 \\
\hline “Corrente” & creme & I & $6,0 \mathrm{~b}$ & $33,7 \mathrm{a}$ & 80,3 \\
\hline "Macotaço" & preto & III & $5,7 \mathrm{c}$ & 35,0a & 84,0 \\
\hline “Minuano” & preto & III & $5,7 \mathrm{c}$ & 33,0a & 77,7 \\
\hline "Macanudo" & preto & II/III & $5,7 \mathrm{c}$ & $32,7 \mathrm{a}$ & 83,0 \\
\hline "Rio Tibagi" & preto & II & $5,7 \mathrm{c}$ & 33,3a & 81,3 \\
\hline "Bambuí" & creme & III & $5,3 \mathrm{c}$ & 35,0a & 84,0 \\
\hline "Carioca Precoce" & carioca & II & $5,3 \mathrm{c}$ & $26,3 b$ & 82,0 \\
\hline “Pérola” & carioca & III & $5,3 c$ & 35,3a & 89,7 \\
\hline “Carioca” & carioca & III & $5,3 \mathrm{c}$ & $36,0 \mathrm{a}$ & 76,3 \\
\hline “Ouro Negro" & preto & II/III & $5,3 \mathrm{c}$ & $28,7 \mathrm{~b}$ & 78,0 \\
\hline “TPS Nobre” & preto & II & $5,3 \mathrm{c}$ & $35,0 \mathrm{a}$ & 83,3 \\
\hline “Goytacazes” & carioca & III & $5,0 \mathrm{c}$ & 35,3a & 83,0 \\
\hline “TPS Bonito” & carioca & III & $5,0 \mathrm{c}$ & 33,0a & 74,7 \\
\hline "IAPAR 31" & carioca & II & $5,0 \mathrm{c}$ & 34,0a & 83,3 \\
\hline "Guateian 6662" & preto & $\mathrm{II} / \mathrm{III}$ & $5,0 \mathrm{c}$ & $34,0 \mathrm{a}$ & 87,7 \\
\hline “Ônix” & preto & II & $5,0 \mathrm{c}$ & $40,7 \mathrm{a}$ & 82,0 \\
\hline "BRS Valente" & preto & II & $5,0 \mathrm{c}$ & $35,7 \mathrm{a}$ & 83,7 \\
\hline "IAPAR 44" & preto & II & $5,0 \mathrm{c}$ & $38,0 \mathrm{a}$ & 87,7 \\
\hline Média & & & 5,5 & 33,0 & 81,8 \\
\hline CV(\%) & & & 7,86 & 7,50 & 6,62 \\
\hline
\end{tabular}

*Cultivares com médias não seguidas por mesma letra na vertical diferem pelo teste Scott Knott ao nível de 5\% de probabilidade; ns: nãosignificativo.

**HC= hábito de crescimento: (I) determinado; (II) indeterminado com guias curtas; (III) indeterminado com guias longas.

de R5 e R7, pré-floração e formação de vagens, respectivamente. Para tanto, a temperatura do ar, no interior do fitotron, foi elevada para $30^{\circ} \mathrm{C}$ e permaneceu nessa condição por uma hora, diariamente. Nos demais estádios fenológicos de desenvolvimento, a temperatura do ar foi mantida a $21^{\circ} \mathrm{C} \pm 1^{\circ} \mathrm{C}$ durante o dia e a $18^{\circ} \mathrm{C} \pm 1^{\circ} \mathrm{C}$ à noite.

As características fenológicas avaliadas foram: número de dias da semeadura à emergência (V1), número de dias da emergência à floração (R6) e número de dias da emergência à maturação fisiológica (R9). As estruturas reprodutivas, quantificadas em cada planta de feijão, foram número total de flores emitidas, número de vagens formadas (considerou-se vagem quando se verificou a presença de pelo menos uma semente apta para a germinação) e, por diferença, obteve-se o número de flores e vagens abortadas. O número total de flores e vagens abortadas, em relação ao número total de flores emitidas, foi considerado como taxa de abortamento, em percentagem, e esse valor foi submetido à transformação angular (arcosen $\sqrt{\mathrm{x} / 100})$. No entanto, os valores originais de percentagem de abortamento foram apresentados. Também foram determinados o número de sementes por vagem e a massa de 100 sementes, a 13\% de umidade média.

Os dados obtidos foram submetidos à análise da variância e as médias foram comparadas pelo teste de Scott-Knott a 5\% de probabilidade.

\section{RESULTADOS E DISCUSSÃO}

Na análise de variância, obteve-se efeito significativo para as características número de dias da semeadura à emergência, número de dias da emergência 
à floração, número de flores emitidas, número de flores e vagens abortadas, percentagem de abortamento, número de sementes por vagem e massa de 100 grãos, evidenciando a existência de variabilidade genética para cultivares.

De maneira geral, maior precisão experimental foi observada para as características fenológicas (Tabela 1). Apesar de terem sido obtidos valores altos e intermediários de coeficiente de variação para as demais características, pôde-se constatar comportamento diferenciado das cultivares de feijão em resposta à alta temperatura do ar no período reprodutivo (Tabela 2). Variabilidade genética para tolerância à alta temperatura do ar também foi constatada em feijão (SILVEIRA et al., 1980; SHONNARD \& GEPTS, 1994; MODA-CIRINO \& FONSECAJÚNIOR, 2001;AGUIAR \& MODA-CIRINO, 2002a; AGUIAR \& MODA-CIRINO, 2002b; SILVA et al., 2005).

As cultivares “Iraí”, "PR 468” e "Corrente” - de hábito de crescimento determinado, tipo I - levaram de 6 a 7 dias para a emergência (Tabela 1). Por sua vez, as demais cultivares de hábito de crescimento indeterminado com ramificações fechadas ou abertas tipo II e tipo III, respectivamente - emergiram em cinco dias após a semeadura.

Apesar do atraso para a emergência verificado para "Iraí" e "PR 468, essas cultivares foram mais precoces para a floração (22,7 dias). Também destacaram-se em precocidade para início da floração, as cultivares "Carioca Precoce” (26,3 dias) e "Ouro Negro” (28,7 dias). No entanto, nem sempre os genótipos que florescem mais cedo foram os de ciclo mais precoce, como já observado por RIBEIRO et al. (2004).

Convém destacar que, no presente trabalho, as plantas de feijão somente foram submetidas à alta temperatura $\left(30^{\circ} \mathrm{C}\right)$, por uma hora, durante $\mathrm{o}$ período reprodutivo, sendo a água e os nutrientes fornecidos em níveis ótimos. Nessa condição, as plantas de feijão apresentam atividade biológica intensa, com crescimento exuberante e alongamento do período de floração, como também constatado anteriormente por AIDAR et al. (2002). Esses fatores contribuíram para o

Tabela 2 - Número de flores emitidas (flores), número de vagens formadas (vagens), número de flores e vagens abortadas (abortado), percentagem de abortamento (abortamento), número de sementes por planta (sementes) e massa de 100 sementes por planta (massa) de cultivares de feijão submetidas à temperatura de $30^{\circ} \mathrm{C}$, por uma hora, durante o período reprodutivo. Santa Maria-RS, UFSM, 2006

\begin{tabular}{|c|c|c|c|c|c|c|}
\hline Cultivares & Flores & Vagens & Abortado & Abortamento \% & Sementes & Massa g \\
\hline "Carioca Precoce" & $36,7 a^{*}$ & $7,7^{\mathrm{ns}}$ & $29,0 a$ & $79,2 a$ & $3,9 b$ & $19,30 \mathrm{~b}$ \\
\hline “PR 468” & $34,7 a$ & 6,0 & $28,7 \mathrm{a}$ & $83,2 \mathrm{a}$ & $3,6 b$ & $37,90 a$ \\
\hline "Iraí” & $34,5 a$ & 3,5 & $31,0 \mathrm{a}$ & $90,0 \mathrm{a}$ & $3,8 b$ & $35,48 a$ \\
\hline “Ouro Negro” & $26,3 a$ & 9,5 & $16,8 b$ & $59,2 \mathrm{a}$ & $4,5 b$ & $28,29 b$ \\
\hline "Rio Tibagi” & $26,3 a$ & 16,0 & $10,3 b$ & $39,8 b$ & $6,1 \mathrm{a}$ & $22,42 b$ \\
\hline “Minuano” & 23,3a & 10,0 & $13,3 b$ & $56,7 \mathrm{a}$ & $5,5 a$ & $26,82 b$ \\
\hline “TPS Nobre” & $21,3 b$ & 9,0 & $12,3 b$ & $55,2 \mathrm{a}$ & $5,6 a$ & $21,32 b$ \\
\hline "Macotaço" & $20,0 \mathrm{~b}$ & 9,0 & $11,0 \mathrm{~b}$ & $51,1 \mathrm{a}$ & $6,3 a$ & $27,74 b$ \\
\hline “Goytacazes” & $18,7 b$ & 12,7 & $6,0 \mathrm{~b}$ & $28,2 b$ & $4,5 b$ & $34,03 a$ \\
\hline “Macanudo” & $17,7 \mathrm{~b}$ & 8,3 & $9,3 b$ & $45,7 \mathrm{~b}$ & $5,9 a$ & $26,33 b$ \\
\hline “IAPAR 44" & $17,3 b$ & 12,3 & $5,0 \mathrm{~b}$ & $32,5 b$ & $5,0 \mathrm{a}$ & $22,69 b$ \\
\hline “IAPAR 31" & $16,0 \mathrm{~b}$ & 6,7 & $9,3 b$ & $59,5 a$ & $5,3 a$ & 25,97b \\
\hline "Pérola" & $14,5 b$ & 9,5 & $5,0 \mathrm{~b}$ & $35,1 b$ & $4,9 a$ & $32,82 \mathrm{a}$ \\
\hline “Guateian 6662” & $14,0 \mathrm{~b}$ & 8,0 & $6,0 \mathrm{~b}$ & $45,3 b$ & $5,3 a$ & $22,03 b$ \\
\hline “Carioca” & $13,7 b$ & 5,0 & $8,7 b$ & $64,4 a$ & $6,6 a$ & $28,53 b$ \\
\hline “Corrente” & $13,3 b$ & 12,7 & $0,7 \mathrm{~b}$ & $5,7 b$ & $4,5 b$ & $31,49 a$ \\
\hline “BRS Valente” & $13,0 \mathrm{~b}$ & 9,0 & $4,0 \mathrm{~b}$ & $25,4 b$ & $5,1 \mathrm{a}$ & $26,23 b$ \\
\hline “Ônix” & $12,3 b$ & 6,0 & $6,3 b$ & $45,5 b$ & $5,2 \mathrm{a}$ & $27,60 \mathrm{~b}$ \\
\hline "Bambuí" & $10,0 \mathrm{~b}$ & 4,7 & $5,3 b$ & $48,6 b$ & $5,0 \mathrm{a}$ & 23,71b \\
\hline “TPS Bonito” & $10,0 \mathrm{~b}$ & 5,3 & $4,7 b$ & $35,3 b$ & $4,1 b$ & 23,10b \\
\hline Média & 19,7 & 8,5 & 11,1 & 49,3 & 5,0 & 27,2 \\
\hline CV (\%) & 44,4 & 50,8 & 57,3 & 30,2 & 15,8 & 18,4 \\
\hline
\end{tabular}

* Cultivares com médias não seguidas por mesma letra na vertical diferem pelo teste Scott Knott ao nível de 5\% de probabilidade; ns: nãosignificativo.

Ciência Rural, v.37, n.6,nov-dez, 2007. 
alongamento do ciclo das cultivares precoces ("Iraí”, "PR 468” e "Corrente”), que apresentaram número de dias para a maturação fisiológica semelhante às cultivares de ciclo intermediário, já que não foram observadas diferenças significativas para ciclo.

As cultivares de feijão que apresentaram maior número de flores emitidas foram: "Carioca Precoce”, "PR 468”, "Iraí”, “Ouro Negro”, "Rio Tibagi” e "Minuano” (Tabela 2). Para o número de vagens formadas, não foi possível a identificação de variabilidade genética, devido ao elevado coeficiente de variação observado.

Com relação ao número de flores e de vagens abortadas, maiores valores foram constatados para “Iraí”, “Carioca Precoce” e “PR 468”. Essas cultivares caracterizaram-se por apresentar mais de 34 flores emitidas e índices superiores a 79\% de abortamento de flores (Tabela 2). As cultivares que floresceram mais precocemente (Tabela 1) foram submetidas a maior número de dias com temperatura de $30^{\circ} \mathrm{C}$, o que contribuiu para o elevado número de flores abortadas.

A aplicação do teste de Scott-Knott permitiu a formação de dois grupos quanto à percentagem de abortamento de flores: grupo 1: 90,0 a 51,1\% de abortamento e grupo 2: 48,6 a 5,7\% (Tabela 2). As cultivares de feijão que apresentaram alta percentagem de abortamento de flores, enquadradas no grupo 1 , foram consideradas de alta suscetibilidade aos efeitos da alta temperatura do ar. No grupo 2, com menores percentagens de abortamento, as cultivares foram classificadas em tolerantes à alta temperatura do ar no período reprodutivo. As taxas de abortamento verificadas estão dentro do esperado para condições de cultivo a campo, que de 50 a 70\% (MARIOT, 1989), podendo superar em 20 a 50\% esses índices em condições de alta temperatura do ar (DIDONET, 2002).

No grupo com tolerância à alta temperatura, convém destacar as cultivares de grãos tipo carioca, que apresentaram menores índices de abortamento de flores - "Pérola” (35,1\%) e “TPS Bonito” (35,2\%) - e com adaptação ao cultivo no Estado do Rio Grande do Sul. No grupo comercial preto, a cultivar "BRS Valente" (25,4\% de abortamento) apresentou menor taxa de abscisão de flores. Para esse grupo, também destacaram-se as cultivares "Iapar 44", "Rio Tibagi”, “Guateian 6662”, “Ônix” e “Macanudo”. No entanto, a utilização da "BRS Valente” é mais indicada para o cultivo no RS, pela maior disponibilidade de sementes, estabilidade de produção e características da qualidade de grãos, que conferem a preferência do consumidor.

Convém destacar a cultivar "Corrente", de tegumento creme, que apresentou $5,7 \%$ de abortamento de flores. Uma hipótese que pode justificar o menor abortamento de flores é a maior disponibilidade de carboidratos (DIDONET \& MADRIZ, 2002). Isso explicaria o baixo abortamento verificado para essa cultivar, que pode ser utilizada para cultivo em regiões onde há maior probabilidade de ocorrência de risco climático para altas temperaturas, pois mostrou-se altamente tolerante. No entanto, na Região Sul, o mercado para esse tipo de grão é insignificante devido ao consumo ser considerado pouco representativo.

As cultivares avaliadas são da espécie Phaseolus vulgaris L., que caracteriza-se pela presença de até oito sementes por vagem. As cultivares “Goytacazes”, “Ouro Negro”, “Corrente”, “TPS Bonito”, “Carioca Precoce”, “Iraí” e "PR 468” apresentaram o menor número de sementes por vagem (Tabela 2).

Em condições de cultivo sob temperatura do ar elevada, tem-se observado a diminuição do número de vagens por planta, do número de grãos por vagem e da massa de grãos, o que afeta negativamente a produtividade (AIDAR et al., 2002). No presente estudo, a redução na massa de 100 sementes não foi observada (Tabela 2). Provavelmente, pelo fato de as plantas terem sido conduzidas em condições ótimas para água e nutrientes, observou-se o menor número de grãos, mas sem alteração da massa de 100 sementes.

Com base nos resultados obtidos sob temperatura de $30^{\circ} \mathrm{C}$ durante o subperíodo, pré-floração e formação de vagens, sugere-se a utilização das cultivares "Pérola" e "TPS Bonito" (grãos tipo carioca), "BRS Valente” (grupo comercial preto) e "Corrente" (grãos de coloração creme) para a utilização em blocos de cruzamentos para o desenvolvimento de cultivares de feijão com maior tolerância à alta temperatura do ar, pois apresentaram baixa percentagem de abortamento de flores.

\section{CONCLUSÕES}

Há variabilidade genética em feijão para tolerância à alta temperatura do ar no período reprodutivo. As cultivares de feijão "Pérola”, “TPS Bonito”, "BRS Valente” e “Corrente” são tolerantes à temperatura do ar de $30^{\circ} \mathrm{C}$, com duração de uma hora, durante o período reprodutivo.

\section{AGRADECIMENTOS}

À Fundação de Amparo à Pesquisa do Estado do Rio Grande do Sul (FAPERGS), pelo auxílio financeiro e pela bolsa de iniciação científica do aluno Nerison Luis Poesch. Ao Conselho Nacional de Desenvolvimento Científico e Tecnológico (CNPq), pela concessão de bolsa aos pesquisadores 
Nerinéia Dalfollo Ribeiro e Sandro Luís Petter Medeiros e à aluna Simone Saydelles da Rosa. À Coordenação de Aperfeiçoamento de Pessoal de Nível Superior (CAPES), pelas bolsas dos alunos Leo Hoffmannn Júnior e Evandro Jost.

\section{REFERÊNCIAS}

AGUIAR, R.S.; MODA-CIRINO, V. Avaliação de linhagens promissoras de feijoeiro do grupo comercial carioca quanto à tolerância ao estresse térmico. In: CONGRESSO NACIONAL DE PESQUISA DE FEIJÃO, 7., 2002, Viçosa, MG. Anais... Viçosa: UFV, 2002a. 842p. p.418-420.

AGUIAR, R.S.; MODA-CIRINO, V. Reação de linhagens promissoras de feijoeiro (Phaseolus vulgaris L.) do grupo comercial preto ao estresse térmico. In: CONGRESSO NACIONAL DE PESQUISA DE FEIJÃO, 7., 2002, Viçosa, MG. Anais... Viçosa: UFV, 2002b. 842p. p.421-424.

AIDAR, H. et al. Mudanças fisiológicas no feijoeiro-comum, sob altas temperaturas, em várzeas tropicais. In: CONGRESSO NACIONAL DE PESQUISA DE FEIJÃO, 7., 2002. Viçosa, MG. Anais... Viçosa: UFV, 2002. 842p. p.76-79.

ANDRADE, M.J.B. Clima e solo. In: VIEIRA, C. et al. Feijão: aspectos gerais e cultura no Estado de Minas. Viçosa: UFV, 1998. Cap.4, p.83-97.

BARBANO, M.T. et al. Comparação entre valores observados e estimados de duração dos diferentes subperíodos de desenvolvimento da cultura do feijoeiro. Revista Brasileira de Agrometeorologia, Santa Maria, v.9, n.1, p.103-110, 2001.

BURIOL, G.A. et al. Cartas mensais e anuais das temperaturas médias, das médias das temperaturas máximas e das médias das temperaturas mínimas do estado do Rio Grande do Sul. Revista do Centro de Ciências Rurais, Santa Maria, v.9, p.1-53, 1979. (suplemento).

DICKSON, M.H.; PETZOLDT, R. Heat tolerance and pod set in green beans. Journal American Society Horticulture Science, Alexandria, v.114, n.5, p.833-836, 1989.

DIDONET, A.D. Acúmulo de biomassa, nitrogênio e temperatura na definição do rendimento de grãos do feijão. Santo Antônio de Goiás: Embrapa Arroz e Feijão, 2002. 37p. (Embrapa. Programa 4 - Sistemas de Produção de Grãos. Projeto 04.2001.074). Relatório de Acompanhamento, período 2001.

DIDONET, A.D. et al. Efeitos da alta temperatura do ar. In:______. Produção do feijoeiro comum em várzeas tropicais. Santo Antônio de Goiás: Embrapa Arroz e Feijão, 2002. Cap.3, p.53-66.

DIDONET, A.D.; MADRIZ, P.M. Abortamento de flores e vagens no feijoeiro: efeito da temperatura e da radiação solar. In: CONGRESSO NACIONAL DE PESQUISA DE FEIJÃO, 7., 2002. Viçosa, MG. Anais... Viçosa: UFV, 2002. 842p. p.5558.
ESTEFANEL, V. et al. Probabilidade de ocorrência de temperaturas máximas do ar prejudiciais aos cultivos agrícolas em Santa Maria. Revista Brasileira de Agrometeorologia, Santa Maria, v.2, n.1, p.57-63, 1994.

GONÇALVES, S.L. et al. Probabilidade de ocorrência de temperaturas superiores a $30^{\circ} \mathrm{C}$ no florecimento do feijoeiro (Phaseolus vulgaris L.), cultivado nas safras das águas no Estado do Paraná. Revista Brasileira de Agrometeorologia, Santa Maria, v.5, n.2, p.99-107, 1997.

HOAGLAND D.R.; ARNON D.L. The water culture methods for growing plants without soil. Berkely: University of California, 1950. 32p. (Circular, 347).

MARIOT, E.J. Ecofisiologia do feijoeiro. In: $\mathbf{O}$ feijão no Paraná. Londrina: IAPAR, 1989. p.25-41. (Circular, 63).

MASSIGNAM, A.M. et al. Ecofisiologia do feijoeiro. II Redução do rendimento pela ocorrência de altas temperaturas no florescimento. Revista Brasileira de Agrometeorologia, Santa Maria, v.6, n.1, p.41-45, 1998.

MODA-CIRINO, V.; FONSECA JÚNIOR, N.S. Seleção de genótipos de feijoeiro (Phaseolus vulgaris L.) tolerantes a alta temperatura. In: CONGRESSO BRASILEIRO DE MELHORAMENTO DE PLANTAS, 2001, Goiânia, GO. Anais... Goiânia: EMBRAPA, 2001. CD-ROM.

PORTES, T.A. Ecofisiologia. In: ARAÚJO, R.S. et al. Cultura do feijoeiro comum no Brasil. Piracicaba: POTAFÓS, 1996. p.101-137.

RIBEIRO, N.D. et al. Variabilidade genética para ciclo em feijão dos grupos preto e carioca. Revista Brasileira de Agrociência, Pelotas, v.10, n.1, p.19-29, 2004.

SILVA, C.F.B. et al. Avaliação de tolerância ao estresse térmico em linhagens de feijoeiro do grupo comercial carioca. In: CONGRESSO BRASILEIRO DE MELHORAMENTO DE PLANTAS, 3., 2005, Gramado, RS. Anais... Gramado: Embrapa Trigo; SBMP, 2005. CD-ROM.

SILVEIRA, P.M. et al. Idade de floração e vingamento de flores em duas cultivares de feijão. Pesquisa Agropecuária Brasileira, Brasília, v.15, n.2, p.229-232, 1980.

SHONNARD, G.C.; GEPTS, P. Genetic of heat tolerance during reproductive development in common bean. Crop Science, Madison, v.34, n.5, p.1168-1175, 1994.

TÉRAN, H.; SINGH, S.P. Comparison of sources and lines selected for drought resistance in common bean. Crop Science, Madison, v.42, n.1, p.64-70, 2002.

VIEIRA, C.O feijoeiro-comum: cultura, doenças e melhoramento. Viçosa: UFV, 1967. 220p. 